\title{
Synaptic contributions to in vitro hippocampal sharp-wave ripples
} Álvaro Tejero-Cantero*1,2, Nikolaus Maier ${ }^{3}$, Jochen Winterer ${ }^{3}$,
Genela Morris ${ }^{3}$, Dietmar Schmitz ${ }^{3,4}$ and Christian Leibold ${ }^{1,5}$

Address: ${ }^{1}$ Department Neurobiologie, Ludwigs-Maximilian Universität, Munich, 80802 Germany, ${ }^{2}$ Graduate School of Systemic Neurosciences, Ludwigs-Maximilian Universität, Munich, 80802 Germany, ${ }^{3}$ Charite, Universitätsmedizin Berlin, 10117 Berlin, Germany, ${ }^{4}$ Bernstein Center for Computational Neuroscience, Berlin, Germany and ${ }^{5}$ Bernstein Center for Computational Neuroscience, Munich, Germany

Email: Álvaro Tejero-Cantero* - tejero@biologie.uni-muenchen.de

* Corresponding author

from Eighteenth Annual Computational Neuroscience Meeting: CNS*2009

Berlin, Germany. 18-23 July 2009

Published: 13 July 2009

BMC Neuroscience 2009, I0(SuppI I):P278 doi:I0.II86/I47I-2202-I0-SI-P278

This abstract is available from: http://www.biomedcentral.com/I47I-2202// 0/SI/P278

(c) 2009 Tejero-Cantero et al; licensee BioMed Central Ltd.

\section{Introduction}

In freely behaving rodents, the hippocampus displays prominent deflections in the local field potential during immobility and sleep. These are called sharp waves, last for about 40 to $60 \mathrm{~ms}$ and are jagged with a fast oscillation, or ripple, of about $200 \mathrm{~Hz}$. Sharp waves have been shown in rats to co-occur with multi-unit replay and preplay patterns following and preceding a learned spatial experience [1-3]. Patterns are compressed in order to fit within the tight temporal frame offered by the sharp-wave ripple complexes. On a cellular level, it is known that both interneurons and pyramidal populations are significantly phase-locked to the ripple phenomenon. Our focus is to understand the coordinated cellular activity that triggers, shapes and terminates the sharp-wave ripple complexes. To this end, we resort to in vitro simultaneous field potential and single-cell voltage clamp recordings on submerged mouse hippocampal slices, where the phenomenon appears with characteristics known from the in vivo situation [4]. Recent pharmacological investigations with this setup (Maier 2009, in preparation) suggest that the intracellular high frequency oscillations are mainly supported by excitatory currents (see also [5]). To test this hypothesis, we have compared the patterns of synaptic input to pyramidal cells during sharp waves under two voltage clamp conditions. The first, at a holding potential of around $-72 \mathrm{mV}$ is representative of a bias towards excitatory input only, since it is close to the reversal potential for inhibition and the other, around -50
$\mathrm{mV}$ is dominated by outward, inhibitory currents while still containing some excitatory activity. Figure 1 shows the cumulative distribution functions of relative ripple powers for excitatory (blue) and inhibitory bias (green). Excitatory synaptic inputs show consistently higher relative power in the ripple band when compared with a mix of excitation and inhibition. To investigate the timing of individual post synaptic currents (PSCs) we estimated putative PSC time via a deconvolution approach. We find that ripple-locked excitation arrives predominantly at the beginning of the sharp wave, whereas inhibition arrives late in the sharp wave. Inhibitory currents are less coupled to the ripples than excitatory ones.

\section{Acknowledgements}

This work was supported by the Bundensministerium für Bildung und Forschung (BMBF, grant numbers 0IGQ0440 and 0IGQ04I0) and the Deutsche Forschungsgemeinschaft (DFG, grant number LE 2250/2-I).

\section{References}

I. Lee AK, Wilson MA: Neuron 2002:36.

2. Foster DJ, Wilson MA: Nature 2006:440.

3. Diba K, Buzsaki G: Nature Neurosci 2007: 10.

4. Maier N, Nimmrich V, Draguhn A: J Physiol 2003:550.

5. Nimmrich V, Maier N, Schmitz D, Draguhn A: J Physiol 2005:563. 


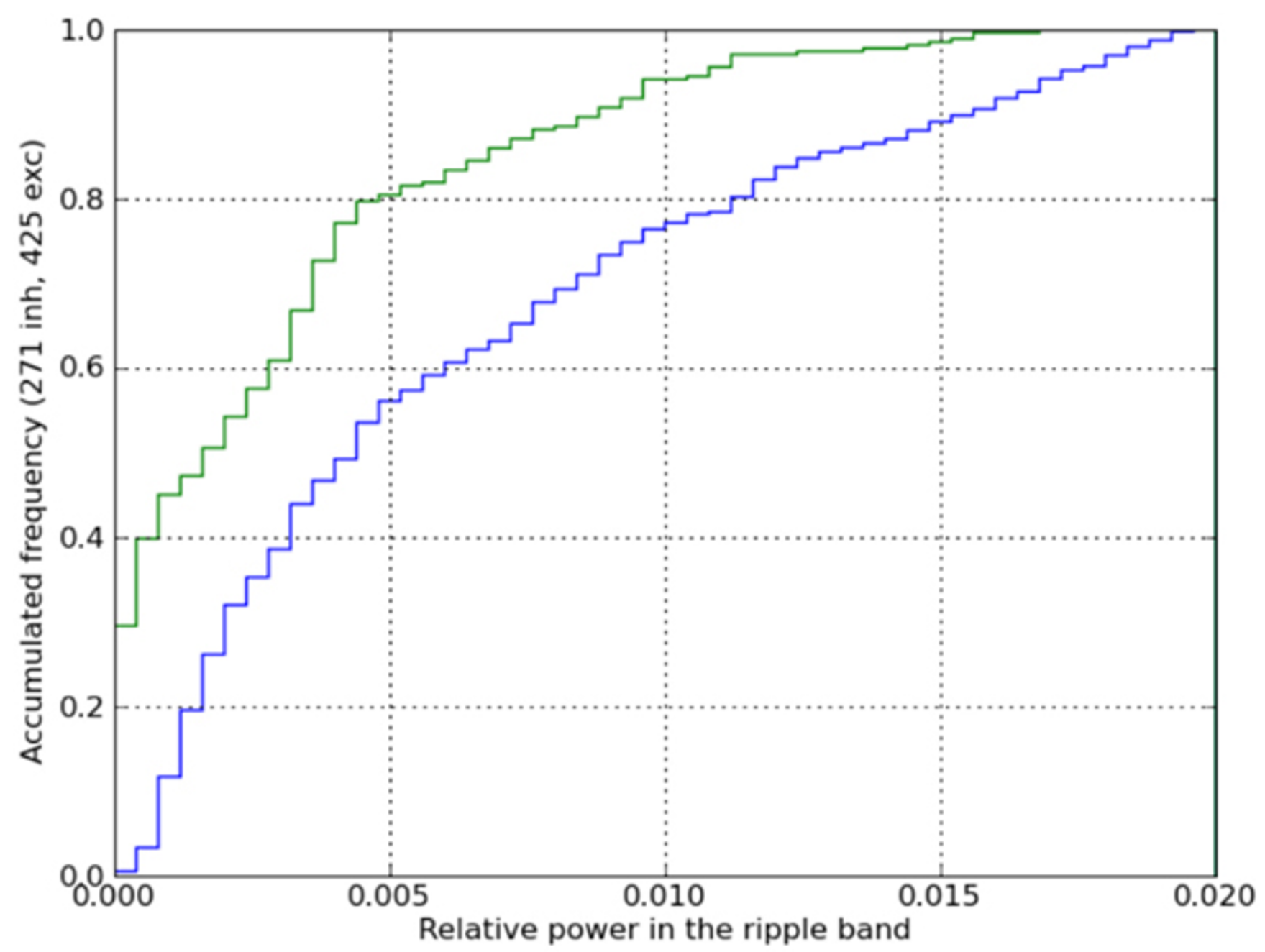

Figure I

Cumulative distribution function of ripple powers in the ripple band $(120-300 \mathrm{~Hz})$ relative to total power. Blue: excitatory bias condition $(-72 \mathrm{mV}), n=425$. Green: inhibitory bias $(-52$ and $-47 \mathrm{mV}), n=27 \mathrm{I}$.

Publish with Biomed Central and every scientist can read your work free of charge

"BioMed Central will be the most significant development for disseminating the results of biomedical research in our lifetime." Sir Paul Nurse, Cancer Research UK

Your research papers will be:

- available free of charge to the entire biomedical community

- peer reviewed and published immediately upon acceptance

- cited in PubMed and archived on PubMed Central

- yours - you keep the copyright 